\title{
Refugee Resettlement: A New Policy
}

"It has been a long pregnancy, but I'm still not sure we're ready to give birth." With these words, Naomi Alboim, Director of Settlement, Ontario Region, Canada Employment and Immigration Commission (CEIC), opened the proceedings in Toronto on November 2nd, 1984 of the Ontario Consultation Conference on Refugee Resettlement.

At the end of the evening, someone suggested to Naomi that, as a mother of twins, she should have been the first to recognize that the consultative process was now going through labour pains and was about to give birth. This was the harshest rebuke heard at the conference. In fact, if you did not know the players, it was difficult to tell who was a government employee and who came from the non-governmental sector. Not only did the consultative process give birth to a proposed revised Refugee Resettlement Policy, but the partnership of the private and governmental sectors had developed into a real marriage.

After the heady romantic euphoria of the 1979-1981 period when the Canadian government, with the immense help of the private sector, managed to bring to Canada and resettle 80,000 Indochinese refugees, the Minister of Employment and Immigration, Lloyd Axworthy, in the spring of 1982 instigated several evaluations of the Indochinese resettlement experience, and a process of consultations to see how the involvement of the private sector could be encouraged to continue. The evaluations indicated that sponsors would again come forward to help if there was a demonstrated need, if better resettlement services were provided, and if there was more government/private sector sharing and a corresponding elimination of the discrepancies between government and private sponsorship.

The consultative process began in earnest. A number of truths were already accepted: a widespread recognition that the voluntary sector could offer benefits and services that the government could not; that private sponsor- ship should continue to augment and not substitute for government sponsorship; that there needed to be more flexibility to allow different degrees of non-governmental involvement, while at the same time, allowing the government to act quickly during an emergency.

The Director of Refugee Resettlement in Ontario instituted a steering committee which determined that more research was necessary to prepare an information package and options. That research had to go further to analyze the cost implications, while ensuring true equalization in the delivery of services, and real cooperation between the private and governmental sectors. A plan of action was instigated and graduate students were recruited to undertake the research. Meanwhile, other regions recommended improvements, including better access to information, non-government involvement with government-sponsored refugees, a process for increasing public awareness, increased counselling and orientation for both refugees and sponsors, better guidelines for sponsors, improved language training and skill training for refugees, funding for NGOs to provide an improved infrastructure, possibly through local refugee councils.

The research undertaken in Ontario by graduate students, in addition to compiling a comprehensive basis of information, also demonstrated that private sponsorship of refugees was significantly less costly than government sponsorship because of a number of factors:

a) much lower furniture costs because most furniture for privately sponsored refugees was donated;

b) lower clothing costs for much the same reason;

c) no initial hotel bills;

d) somewhat lower housing costs, primarily because singles were often accommodated in homes free of charge and some housing was donated; e) a shorter period in obtaining em ployment and achieving self-suffeciency because of the network system of volunteers which assisted th refugees in obtaining employmen more quickly.

In other words, the savings in settle ment costs of 50 to 60 percent were no the result of bureaucratic inefficienct or extravagance, but simply due to thit fact that volunteer members of the community could do certain things that no civil servant could be expected do. At the same time, the private spor sors were an important component if the orientation and adaptation of th refugees to Canadian life.

The publication of "Federal Govern ment Perspectives on Refugees" in 198 gave recognition to the role of the pre vate sector. In March 1984, the firs consultative conference on resettlemen to forge a new policy and partnershir was held in Ontario. Individuals with experience and expertise attended from government, service delivery agencie religious and ethnic organizations anc academia. Invitations were extende for the submission of new models and seven were received. At the conference these models were analyzed and of tiqued yet not one survived intact as suitable basis for a new refugee rese tlement policy. Out of the discussion however, an approach to resettlemes: emerged with the following commo elements.

Minimum standards and guidelin needed to be established which wou be familiar to all. The refugees had be involved as much as possible in resettlement process. Long-term as w as short-term resettlement needs had be taken into consideration. Certa specific needs were highlighted - be ter assessment of the refugees on arrive improved backup services for orient tion for both refugees and sponsors need for day-care facilities, dental p grams and mental health assistang Most importantly, there was agreeme that every refugee should have the $b$ 


\title{
A Revised Program of Refugee Resettlement in Canada
}

\author{
(A very abbreviated version)
}

The following model is based on the research proposals and the results of the consultation conference. It is a product of the cooperation of academics, the non-governmental sectors and government officials, which developed a consensus on the need to develop the key components of the resettlement process:

a) Host group as an option available to government-sponsored refugees to assist them in resettlement;

b) Local refugee councils which can act as coordinators of community efforts in refugee resettlement, and serve to stimulate the development of host groups and sponsors while acting also as a backup resource for those families, sponsoring groups and sponsors of family members.

\section{The Host Group}

The host group may be an individual or family. It is expected that the host group will take a personal interest in the ongoing welfare and social development of the refugee. It is the primary responsibility of the host group to undertake the cultural integration and social adaptation of a refugee family for a minimum of a year in accordance with specified tasks set out in agreement with the community refugee council. Certain minimum tasks would include:

- to help with a refugee's understanding of and access to Canadian institutions and systems;

- to assist in locating housing, furnishings and employment;

- to support the individual needs and wishes of the refugee to the extent possible.

A host group will have access to government for direct concerns, but it is expected that the host group will seek general advice from the community council.

The Local Community Refugee Council The local community refugee council would be based on a defined and coherent area such as London, Ontario or a borough within Metropolitan Toronto to allow cohesive work to be undertaken in facilitating the development of host groups and coordinating support for refugees. The council, while varying somewhat in its makeup from community to community, would consist of the various agencies providing services to refugees, refugee organizations, sponsorship groups and other individuals actively involved in the resettlement of refugees and committed to coordinating efforts on behalf of the resettlement of refugees. Local federal government officials would be in attendance as observers at the meetings. The councils would be eligible to enter into an agreement with the government for the following services:

- to coordinate, stimulate, promote and identify the CEIC host groups and private sponsors;

- to provide orientation to these host groups and sponsors;

- to provide ongoing consultation and advice to host groups and private sponsors;

- to participate in public education and awareness of refugee issues;

- to ensure appropriate intervention in cases of host group or private sponsor breakdown;

- to engage in community refugee resettlement review and to promote improvements in the provision of services;

- to develop a mechanism on a community basis to assist in the provision of furniture, clothing, housing and employment;

- to develop a local set of guidelines based on the nationally determined minimum standards for host groups and sponsors as well as an inventory of resources available to hosts, sponsors and refugees;

- to develop a community response for areas of special need, if not covered by existing programs. Such areas of special need may include family reunification, day-care assistance, mental health programming, recreation programming, interpreter recruitment to assist host groups and sponsors, tacilitating the development of mutual-aid associations for specific refugee groups if required, etc.;
- to maintain accurate statistics, financial records and narrative descriptive records for monitoring and evaluation purposes.

\section{Pilot Projects}

In order to facilitate the development of local community refugee councils across Canada, several pilot proects would be implemented in different locales so that the pilot study would be national in scope. The local area selected would have a past record of refugee settlement and be an area designated for future refugee resettlement.

\section{Independent Evaluation}

In addition to initiatirig several pilot projects, the committee recommends that an independent evaluation be arranged to prepare background studies on the areas selected for pilot studies, including in that background documentation the role of the local CEIC, the different existing service agencies and refugee groups, the general record of relationships among those groups, as well as the past record of refugee resettlement in that area. It would describe and assess the mode of organization developed in that pilot area and would undertake a comparative study of success (or failure) in implementing the proposed program of the local refugee council. The study would also include the cost assessment comparing settlement costs where host groups were involved and those in which they were not. The inclusion of user evaluations of the program, including hosts, councils, CEIC officers, and refugees would be crucial to such a study. The individual would be given a travel stipend to visit each of the pilot areas at least three times during the process of the study. It is envisioned that this evaluator would also play the role of animator as he/she would carry news it one pilot project to another, thereby allowing all the projects to benefit trom each other's experiences during the developmental process.

(C) Authors, 1984. This open-access work is licensed under a Creative Commons Attribution-NonCommercial 4.0 International License, which permits use, reproduction and distribution in any medium for non-commercial purposes, provided the original author(s) are credited and the original publication in Refuge: Canada's Journal on Refugees is cited. 
etit of a Canadian host who would help provide orientation, friendship and help meet the social and recreational needs of the refugees.

Given the agreement on general themes and needs, there was also a recognition that no monolithic model of resettlement was appropriate. But a gap needed to be filled in the panoply of family sponsorship, joint assistance for needy cases, private sponsorship and government-sponsored refugees. The latter would greatly benefit from a voluntary sector link with a host group, with that host group encouraged and supported by a community backup structure.

The questions left open from the consultation were who would encourage the emergence of hosts as an option for government-sponsored refugees, how would the community infrastructure be developed, and how could both of these initiatives be funded while ensuring the equalization of delivery of services to all refugees? A committee was constituted to explore the subject further and to develop a model within these parameters.

At the consultation on November 2 and 3, 1984, Kathleen Ptolemy introduced the new proposed model (see App. 1). The key element she stressed was the host group. (The original term was a host family, but was revised in the conference to designate the host as a host group of three to six individuals, rather than implying it was to be a single family.) The host group would act to ensure equal access to services. In addition to assisting in the adaptation of the refugees and facilitating access to structures and resources, the host would have the support of a community infrastructure. The model did not depend on a one-to-one case basis for handling refugees, but was to be rooted in the community as an essential element in refugee adaptation.

Gord Barnett, Director of the Settlement Branch of CEIC in Ottawa, sent out a memo for discussion to all regions (App. 2), and reported on the comments received from other regions of the country which had conducted consultations and received the Ontario re-

Appendix 2

\section{Host Group Assistance Program for Refugees}

Although there are many elements to the model, the focus for CEIC involvement is simple - to obtain assistance (not financial) in settling the governmentsponsored refugees;

This objective is based on the following:

- privately sponsored refugees do benefit from the social contacts and community orientation provided by private sponsors;

- to give government-sponsored refugees these benefits, host groups or friendship families are required.

- CEC and CIC managers would have difficulty identifying and providing orientation, etc., for these groups due to lack of resources:

- some form of organization is required to identify (approve) the host groups to the CEIC, to provide orientation to host groups, etc.;.

- since these are government-sponsored refugees, Canada should provide financial assistance to establish or assist the organization which will provide the host groups:

- the funds for this financial assistance have been obtained by transferring funds from the AAP (Adjustment's Assistence Program) on the premise that a host group assisting refugee will result in less AAP cost (less cost for furniture. clothing and earlier employment 1 .

gion's proposed model as a basis for a discussion. How would family-sponsored refugees be assisted by the community? Would the hosts be able to name the refugees they helped, thereby complicating the whole process of selection, in assigning refugees to a region of the country? Would it be possible tor a single host family to exploit an individual refugee? How would standards be established across the country to prevent the emergence of gross inequities? CEIC counsellors did not have the time to deal with the complaints of a host family as well as the problems of the refugee. Wasn't there a possibility that the community councils would just lead to another level of bureaucracy in
The program itself could be developed in a number of ways:

- through a community refugee council (along the lines of the attached model). - through the church groups who have signed umbrella agreements for private sponsorship;

- through a combination of the two: church groups or one local church identifies families; and ISAP agency provides families with orientation and support.

In anticipation of these developments, some months ago a proposal was made to cabinet. Cabinet agreed that up to $\$ 250,000$ for fiscal year $1984 / 85$ and up to $\$ 500,000$ for fiscal year $1985 / 86$ be taken from the AAP to test the host group resettlement proposal. It was proposed to cabinet that the funds be allocated to organizations or church groups on the basis of up to $\$ 500$ per refugee or refugee family. At this time, National Headquarters would have these funds allocated through a contribution system, which would allow an organization a great deal of scope in expending the money on resettlement opportunities for refugees, (i.e. hiring a community liaison officer, providing services to host groups, paying out-of-pocket expenses of host groups, paying for rent or publicity campaigns)

the process of resettlement? Was purpose of the proposal to cut cos. and thereby increase numbers of ref gees brought into Canada, or to prove the services to those refugees which Canada had already made commitment? Would the host syste reduce private sponsorship even ther? In his presentation, Mr. Barn also made clear that the host model $v$ not to be confused with the Joint Ass tance Program for needy cases, would the costs of the initiative in a way come from the present IS (Immigrant Services Aid Progra Funds. Headquarters developed alternative model (see App. 3).

(C) Authors, 1984. This open-access work is licensed under a Creative Commons Attribution-NonCommercial 4.0 International License, which permits use, reproduction and distribution in any medium for non-commercial purposes, provided the original author(s) are credited and the original publication in Refuge: Canada's Journal on Refugees is cited. 


\title{
Host Group Assistance Program for Refugees
}

\author{
Resettlement Branch, CEIC (edited)
}

\section{Background}

One of the main thrusts of the Steering Committee's model, developed in the Revised Program of Refugee Resettlement in Canada paper, is the creation of a local community council which would seek to mobilize in a formal manner the resources of the community. If the development of the community council is considered as a secondary component,

\section{Alternative Models}

1. The Signators of Umbrella Sponsorship Agreements

As long as the organization (for the most part these were national church groups and parish groups) is able to provide to the host group and the CEIC the services and support identified in a general way earlier in this paper, agreements could be signed with the umbrella organizations. Some organizations would not be suitable as they would not have the ability to provide the community-level support that will be required by host groups. Others may not have the needed expertise to provide the orientation training, etc. There are, however, a

\section{Funding the Models}

Given that the clients of the host group program would be government-sponsored retugees, CEIC would provide funding for the program. Funding could be provided in the form of a contribution to pay for such costs as establishing the coordinating capability in the community the council or simply a community liaison worker) training the host groups,

\section{Pilot Projects}

There will continue to be a great deal of uncertainty about particular elements of the program until it is field tested. Consultation and discussion will not provide and if we seek only to meet the prime component of the Steering Committee's model, which is to assist government sponsored refugees to resettle, other models suggest themselves.

Models that do not have as a requisite the development of a formal community council should be considered, as in certain communities the council would not

\section{$\diamond \diamond \diamond$}

number of these groups that could fulfill the role. This model would likely have CEIC providing a certain level of funding for each host group identified, trained and matched with a refugee family. In smaller communities, where refugee arrivals are very low (one to five families) and no community organization exists, this may be the only way host groups can be identified and trained.

\section{Voluntary Agencies Currently} Providing Services to Immigrants

ISAP agencies now funded by CEIC could likely provide the services and support required for a host group program. The difficulty faced by these agen-

$$
\diamond \diamond \diamond
$$

providing ongoing services to the host groups, defraying the expenses incurred by the host groups and other expenditures associated with providing settlement assistance.

A ceiling would be required for the contribution agreements and a funding formula would have to be developed. The simplest would be to set a maximum contribution for each refugee (single) or refugee family assigned to a host group.

\section{$\diamond \diamond \diamond$}

the answer to such questions as: are there sufficient numbers of groups wanting to help refugees, what funding level will be required to enable a coordinating mechanism to play the role proposed, will any savings to income support be be required or in other instances forcing the development of the council could be disruptive. Keeping in mind that the primary objective is to assist government-sponsored refugees through a hust group program, it might be best to simply take advantage of the existing ongoing community support rather than to use resources to create a new support mechanism.

cies may be the recruiting of host groups as, unlike the churches, they do not have a membership from which to draw volunteers. On the other hand, they may be best suited to provide the training for host groups and the support host groups will require.

\section{Local Church and Voluntary Agency}

A mixing of the two models above, but requiring a local church rather than a national body. This would be very close to the community council described in the Steering Committee's model but it is envisaged as being less formal: simply the joining of the two groups to identify, train and support host groups.

The potential contribution to the coordinating organization could be calculated by multiplying this contribution by the number of refugees destined to the community. Advances to assist in organizing the program could be made based on the number of expected arrivals and the number of expected host groups. Payments would be made based on an invoice describing the expenditures incurred.

achieved through host families, will the proposal or some version of it work in all sizes of communities, how will we monitor the program, etc? From five to ten pilot projects will be required before any national program is launched.

(C) Authors, 1984. This open-access work is licensed under a Creative Commons Attribution-NonCommercial 4.0 International License, which permits use, reproduction and distribution in any medium for non-commercial purposes, provided the original author(s) are credited and the original publication in Refuge: Canada's Journal on Refugees is cited. 
George Cram presented the brief of the Interchurch Committee which was an attempt to establish definitions and parameters rather than to develop a specific model (see App. 4).

The conference reconvened on Saturday morning, and received an excellent presentation by a panel from the London area (Bev Ashton from Metropolitan United Church, London; Debbie Ashford, a settlement counselor at CEIC in London; and Beth Tellaeche, from the London Cross Cultural Learners (entre). This group had already developed a host program, but because of limited personnel to concentrate on such an area and some limitations in the system of informal cooperation, hosts were only available for about 50 percent of the refugees settling in the London area. The London group presented the history of their program and the guidelines they provided to aid hosts in orienting government-sponsored refugees. They also added an important piece of information on the question of whether the development of a host program would reduce private sponsorship for refugees. Their impression was that the host system increased private sponsors by exposing individuals to a non-risk experience while raising their awareness, and involving them in the lives of refugees whose families might need sponsorship support. However, not only was the London group limited to matching half the refugees with host groups, but they were unable to reach out very effectively (though they held public awareness programs twice per year) to individuals who were not organizationally affiliated.

A number of points emerged from the presentation. London had been able to develop a uniformity in the information and services for privately sponsored, family-sponsored and government-sponsored refugees. The process required a community team effort involving the churches, service agencies, the government and a resource center providing information and educational services. The host program involved a great deal of work with volunteers who required a support system for orientation, but the limited resources had restricted the program not only to half the refugees, but to specific refugee groups - the Indochinese and Central Americans. The program was not able to reach out to refugees who had even less support from their ethnic groups. What, in effect, had been accomplished in London was the institutionalization of a host program, which required extensive community interaction, within an informal structure. The London group proposed a model for formalizing what they had developed, and for a community settlement officer to develop the program, who would be responsible to a community group that would involve the local CEIC settlement officer. The London group also made clear that they believed there were savings in settlement costs (though not as extensive as that of private sponsorship) through shorter hotel stays, quicker job placement and donations of clothing. They found organizing furniture donations to be beyond their resources.

The program also was assisted greatly when the central body of the religious institutions involved, as exemplified by the Baptists, provided a clear policy siatement and direction for support of host groups for refugees. Yet the stimulation of hosts and the support systems had to be locally based in the community, involving at times the interaction of three different religious denominations to assist a particular refugee family. The host system also prevented exploitation by involving three or more different individuals on the host group.

In effect, the London group was able to answer many of the queries raised by Gord Barnett's cross-Canada consultation - the equalization of assistance to all refugees, however sponsored; the connecting of named refugees with the private sponsorship program to augment sponsorship and refugee intake in general without diminishing or complicating the government sponsored program and the host system; the mode of preventing exploitation; the mode of setting community-based (rather than Canada-wide-based) standards; the unwarranted nature of the fears of increased bureaucratic complications: and improved services while cutting some costs.

The conference then divided into five groups provided with a set of functions involved in resettlement, as well questions about those functions. The groups were asked to begin their dis cussions at different points so that the whole list could be covered. The groups reported back to the plenary in the early afternoon.

Following the reports from groups, an animated discussion emerged centering on a perception that the host concept dealt with some issues, but the modef used should enable the community to respond to all refugee needs and not just government-sponsored refugect needs. Flexibility was required, but standards, guidelines and some degree of uniformity were needed in som areas. Recognition had to be given to using and strengthening existing re sources and agencies, and new struct tures should not be imposed. The fol lowing specific recommendations could be considered the essence of the conf sultation:

\section{Recommendations}

1. Public awareness to be increased through the development of informat tion programs, networks and by using the media to involve both community based organizations, federal and inter: national agencies.

2. An evaluation of programs, pilot and existing, be conducted by indepen dent outsiders with the governmen setting aside funds for regular reviewi. and evaluations.

3. A paid professional volunteer $c \hat{c}$ ordinator be appointed in each com munity that warrants to facilitate host group program, without restrictifi: the coordinator, in any way, to simp that role.

4. The structure of community coot nation for the infrastructure supps for the coordinator should remain fle ble, and related to the nature of local community.

5. The government was to remain agent of final responsibility. 


\section{The Churches Involvement in Refugee Resettlement}

\section{Definitions}

1. Friendship Family: An individual/ family relationship between a refugee family and persons who connect to them informally, often built around specific needs, no contractual agreement exists.

2. Host Group: A formal arrangement which exists between a governmentselected refugee family and a Canadian group (five individuals, parish, etc.). It would be similar to present agreements without financial/legal obligations and would focus on provision of human support and orientation.

3. Formal Sponsorship: A formal arrangement for the bringing to Canada of specifically named refugees over and above government programs. Similar to the present program, it would involve financial/legal obligations.

The remainder of the afternoon focused - on the precise mode of funding the host group coordinator, and the mechanism to enable that coordination to take place, given that the model was no longer dependent on the formation of a community refugee council. Should the funding go to a community agency; an NGO in the community where funding would be based on a per capita basis (so many dollars per host group developed), on a service-contract basis for would often require some form of provincial government approval. Their needs would be greater than those which could be met by normal government assistance and host group services. Financial over-and-above obligations would be part of these agreements which would be done on a case-by-case basis.

\section{$\diamond \diamond \diamond$}

\section{Shared Responsibility}

The resettlement of every refugee in Canada is the shared responsibility of the government and private sector, working in partnership to ensure the successful reception and integration of refugees in Canadian communities.

\section{Partners Contribute What They can do Best}

The several partners which contribute to the resettlement of refugees should be allowed to contribute what their particular organizational form, powers, insights, and limitations allow them to do best. Partnership responsibilities should be determined according to the skills, and limitations of each partner.

It is the proper role of government, acting within the provisions for consultation stipulated in the Immigration Act, in ac- cord with the shared responsibilities of the people of Canada, to determine policy, selection criteria and admissions, and to determine settlement need, with adequate finances to accomplish these tasks.

It is the role of the voluntary sector to share with government those tasks which government cannot adequately do by itself, such as the personal care required to adequately settle refugees and integrate them into a new community.

It is the particular responsibility of the non-governmental partners to provide leadership and concrete action in those areas where it is inappropriate or less effectual for government to act.

\section{Put Need First}

The needs of the refugee should be the dominant factor in determining their resettlement program. The refugee should participate in the process of determining decisions re: language training, level of employment, etc.

\section{Equity in Basic Material Needs}

The level of assistance provided to refugees should be consistent with local norms. Provision of basic material needs should be on as equitable a basis as possible for all. the provision of specific host orientation and coordination of functions, or on a project basis, evaluating subsequently whether, in fact, the financial savings and improved services warranted the new development? Essentially, the differences boiled down to a concern with the mechanisms for obtaining funds from the Treasury Board and the desire to ensure results, versus the concern that the mechanism would end up distorting a concern with pro- viding services to all the refugees resettled and not just the governmentsponsored ones. Out of this discussion, it was agreed that at least one of the pilots would be project funded, rather than initiated on a per capita basis, and the independent evaluation could compare the results of this mode of funding a community resettlement coordinator versus a per capita or a service-contract basis. 